\title{
O GÊNERO NOTÍCIA: DIAGNÓSTICO E INTERVENÇÃO'
}

Silvia Regina Emiliano $^{2}$

Resumo: Este artigo parte de uma pesquisa diagnóstica realizada na Universidade Estadual de Maringá, nos anos de 2004/2006 e apresenta como tema o ensino de gramática no curso de Letras/UEM e seus reflexos na prática pedagógica dos professorandos. Nosso objeto de investigação é o curso de Letras. A pesquisa subsidia-se na perspectiva sócio-histórica de linguagem e revela-se qualitativo-interpretativa, de cunho etnográfico e de natureza aplicada. A partir deste diagnóstico, temos como objetivo apresentar uma proposta de intervenção para o ensino-aprendizagem do gênero notícia, trabalhado em sala de aula por dois sujeitos da pesquisa. Assim, a proposta surge a partir de observação e relato de cinco aulas ministradas por duas professorandas, numa sétima série do ensino fundamental, quando estas realizaram a regência. Ancorados na abordagem bakhtiniana dos gêneros dircursivos, indicamos caminhos, para o estudo do gênero notícia, em uma sequiência didática. Este trabalho está vinculado ao Grupo de Pesquisa "Interação e escrita no ensino e aprendizagem" (UEM/CNPq www.escrita.uem.br) e ao projeto de pesquisa "A escrita e o professor: interações no ensino e aprendizagem de línguas".

Palavras-chave: curso de Letras; diagnóstico; intervenção; gênero notícia. 


\section{Introdução}

À luz da Lingüística Aplicada, este artigo apresenta um recorte de uma pesquisa diagnóstica, cujo tema é o ensino de gramática, no curso de Letras/UEM, e seus reflexos na prática pedagógica dos formandos. Subsidiada também na perspectiva sócio-histórica e ancorada nos pressupostos de Bakhtin e Vygotsky, teve como objetivo averiguar as concepções de ensino de língua, de língua, linguagem e de gramática que davam suporte às aulas ministradas pelos futuros professores, para verificar de que forma a abordagem dos conteúdos apreendida na graduação reflete na sua ação docente. Para isso, foram relatadas e analisadas seis aulas realizadas por duas duplas e por um trio de alunos, durante a realização da regência, no estágio supervisionado, em 2004, quando esses acadêmicos cursaram a disciplina Prática de Ensino de Língua Portuguesa, no período matutino. Além disso, observaram-se e relatam-se as aulas de Língua Portuguesa oferecidas pelos professores responsáveis pela formação dessas alunas durante os anos de formação, considerando as ementas das suas disciplinas e o projeto político pedagógico do curso, construindo-se, assim, a triangulação dos dados. No que tange as aulas das professorandas, os resultados mostram um momento de interface entre as abordagens de ensino tradicional e interacionista.

A partir disso, apresentamos uma proposta de trabalho com a notícia, gênero usado em sala pelas professorandas. Salientamos que não queremos expor receitas, mas indicar pistas para abordagens de conteúdos, rever posturas de ensino e instar reflexões a respeito dos conteúdos ensinados e de questões que envolvem a formação inicial do professor, como a transposição didática.

\section{Pressupostos teóricos}

É preciso lembrar que, se o objetivo do ensino de Língua Portuguesa é formar falantes, leitores e escritores competentes, não se deve enfatizar um ensino voltado apenas para o aspecto formal da língua, pois, Bakhtin/Volochinov (1992) salienta que a expressão, definida como 
aquilo que se forma no psiquismo do indivíduo e se exterioriza para outrem com a ajuda de algum código de signos exteriores, comporta duas facetas: o conteúdo - que é interior -, e sua objetivação exterior a forma -, de modo que ambos caminham juntos. "É preciso eliminar de saída o princípio de uma distinção qualitativa entre o conteúdo interior e a expressão exterior" (BAKHTIN/VOLOCHINOV, 1992, p. 112). Contudo, enfatiza que, " exteriorizando-se, o conteúdo interior muda de aspecto, pois é obrigado a apropriar-se do material exterior, que dispõe de suas próprias regras, estranhas ao pensamento interior" (1992, p. 111). Em outras palavras, é o social, a expressão exterior, agindo sobre o individual e, conforme o autor, não é tanto a expressão que se adapta ao nosso mundo interior, mas o nosso mundo interior que se adapta às possibilidades de nossa expressão, aos seus caminhos e orientações possíveis, de maneira que um aprendiz, ao exteriorizar algo o fará, na medida em que isso the foi proporcionado. Assim, se ele não consegue escrever um texto e sim um amontoado de frases, provavelmente o mundo externo, a escola, levou-o a incorporar os aspectos lingüísticos e que formam um texto de modo fragmentado, ou ainda, ele pode ser fruto de um ensino gramatical de caráter puramente prescritivo.

Surge então a objeção do autor com relação ao subjetivismo individualista, porque, segundo ele, o centro organizador de todo evento comunicativo, de toda expressão está situado no meio social que envolve o indivíduo, pois

A verdadeira substância da língua não é constituída por um sistema abstrato de formas lingüísticas nem pela enunciação monológica isolada, nem pelo ato psicofisiológico de sua produção, mas pelo fenômeno social da interação verbal, realizada através da enunciação ou das enunciações. A interação verbal constitui assim a realidade fundamental da língua (BAKHTIN/VOLOCHINOV, 1992, p. 123).

Nessa perspectiva, a linguagem é mais do que apenas um meio de comunicação. Aliás, como reflete o autor, essa é a sua função secundária, porque a palavra é um signo social e não deve ser encarada como algo estanque, neutra, dissociada das práticas discursivas da linguagem, uma vez que esta é uma roupagem; o que prova que a 
linguagem não se caracteriza essencialmente como expressão do pensamento e, sim, como agente, pois está a serviço de uma prática social. Portanto, ela atua e modifica o outro.

A palavra dirige-se a um interlocutor: ela é função da pessoa desse interlocutor: variará se se tratar de uma pessoa do mesmo grupo ou não, se esta for inferior ou superior na hierarquia social, se estiver ligada ao locutor por laços mais ou menos estreitos (pai, mãe, marido, etc). Não pode haver interlocutor abstrato; não teríamos linguagem comum com tal interlocutor, nem no sentido próprio nem no figurado [...] $\mathrm{Na}$ realidade, toda palavra comporta duas faces. Ela é determinada tanto pelo fato de que procede de alguém, como pelo fato de que se dirige para alguém. Ela constitui justamente o produto da interação do locutor e do ouvinte. Toda palavra serve de expressão a um em relação ao outro. Através da palavra, defino-me em relação ao outro, isto é, em última análise, em relação, em relação à coletividade. A palavra é uma espécie de ponte lançada sobre mim numa extremidade, na outra apóia-se sobre o meu interlocutor. A palavra é o território comum do locutor e do interlocutor (BAKHTIN/VOLOCHINOV, 1992, p. 112-113).

Assim, na linha que vê a linguagem somente com forma de expressão do pensamento, o papel do outro é visto apenas como papel de ouvinte, aquele que compreende passivamente o falante (BAKHTIN, 2003) e até hoje ainda existem na linguiística ficções como o "ouvinte" e o "entendedor". Como observa Bakhtin, tais ficções dão uma noção absolutamente deturpada do processo complexo e amplamente ativo da comunicação discursiva. Contudo, não se pode afirmar que seja essa uma noção falsa e que não corresponda a determinados momentos da realidade, principalmente em situações de ensino, pois, embora Bakhtin não tenha direcionado a ele seus estudos da linguagem, sabe-se que muitas vezes é necessário assumir uma postura tradicionalista e estruturalista em sala de aula. Nesse sentido, o quando e o como fazer requerem sempre um cuidado, porque atividades sustentadas nessas posturas não constituem a natureza fundamentalda linguagem. Ao passar ao objetivo real da comunicação discursiva, a noção de ouvinte e 
entendedor, ou transmissor e receptor, se transforma em ficção científica, de modo que o outro, ao perceber e compreender o significado (lingüístico) do discurso, ocupa em relação a ele uma ativa posição responsiva, o que significa concordar ou discordar dele, completá-lo, aplicá-lo preparar-se para usá-lo etc, porque “[...] toda compreensão da fala viva, do enunciado vivo é de natureza ativamente responsiva (embora o grau desse ativismo seja bastante diverso), toda compreensão é prenhe de resposta, e nessa ou naquela forma a gera obrigatoriamente: o ouvinte se torna falante", pois "[...] toda compreensão plena real é ativamente responsiva e não é senão uma fase em que ela se dê" (2003, p. 271). Isso porque, explicita o autor, mesmo que a palavra não pertença totalmente ao locutor, ou ao outro, uma vez que ela se situa numa espécie de zona fronteiriça, cabe-lhe, entretanto, uma boa metade. Em um determinado momento, o locutor é incontestavelmente o único dono da palavra. É o que Bakhtin chama de instante do ato fisiológico de materialização da palavra. Porém, salienta que o próprio falante está determinado precisamente a essa compreensão ativamente responsiva; portanto, ele não espera uma compreensão passiva, mas uma resposta, seja uma concordância, uma participação, ou uma objeção. É o caráter dialógico da linguagem, vista como ação entre dois ou mais falantes. É um jogo discursivo cujas peças essenciais são a palavra e a contrapalavra.

Dessa forma, a palavra existe para o locutor sob três aspectos: neutra e não pertencente a ninguém; do outro e preenchedora dos ecos dos enunciados alheios; minha, porque, uma vez que uso essa palavra numa situação comunicativa, nela já está impregnada minha expressividade. Como evidencia o autor, a palavra adquire valor lingüístico num contexto de enunciações precisas, o que implica sempre um contexto ideológico preciso. Portanto, está sempre carregada de um conteúdo ou de um sentido ideológico ou vivencial. Enunciação definida como a situação concreta de comunicação e que, portanto, engloba os aspectos social, histórico e ideológico em que é proferido o discurso.

Bakhtin (2003, p. 283) observa que "[...] aprender a falar significa aprender a construir enunciados (porque falamos por enunciados e não por orações isoladas e, evidentemente, não por palavras isoladas)", e nem por exercícios aplicados divorciados das práticas de usos efetivos da linguagem. "A oração enquanto unidade da língua é desprovida da 
capacidade de determinar imediata e ativamente a posição responsiva do falante", pois "só depois de tornar-se um enunciado pleno, uma oração particular adquire essa capacidade" (p. 287). Aliás, enfatiza o autor que "[...] a língua passa a integrar a vida através de enunciados concretos (que se realizam); é igualmente através de enunciados concretos que a vida entra na língua" (BAKHTIN, 2003, p. 265). Entenda-se enunciado como a unidade real da comunicação discursiva. Isso porque, à luz de Bakhtin, o discurso só pode existir de fato na forma de enunciações concretas de determinados falantes, os próprios sujeitos do discurso, e não fora desta.

Desse modo, a utilização da língua efetua-se em forma de enunciados (orais e escritos), concretos e únicos, que partem dos integrantes da atividade verbal em uma ou outra esfera. Assim, o enunciado reflete as condições específicas e as finalidades de cada uma dessas esferas, não só por seu conteúdo temático e por seu estilo verbal, mas também e, principalmente, por sua construção composicional. São estes três elementos que, fundidos no enunciado, marcados pela especificidade de uma esfera de comunicação, formam os gêneros do discurso. Como mostra o autor, cada campo de utilização da língua elabora seus tipos relativamente estáveis de enunciados, o que ele denomina de gêneros do discurso.

A riqueza e a diversidade dos gêneros do discurso são infinitas porque são inesgotáveis as possibilidades da multiforme atividade humana e porque em cada campo dessa atividade é integral o repertório de gêneros do discurso, que cresce e se diferencia à medida que se desenvolve e se complexifica um determinado campo. (BAKHTIN, 2003, p. 262).

Val (2003) assinala que os gêneros estabelecem formas típicas de organização dos discursos e cita como exemplo o gênero carta comercial, no qual podemos reconhecer uma forma composicional típica constituída de data, endereçamento, vocativo, cumprimento, corpo do texto, despedida e assinatura. Os gêneros estabelecem também pautas temáticas e formas típicas para o seu tratamento, além de um estilo que é orientado no processo de recursos lexicais e morfossintáticos. 
Bakhtin (2003) apresenta os gêneros em duas categorias: gêneros primários e secundários. Os primários são simples, nascem na sociedade. Manifestam-se na fala e na escrita. Entre eles estão o diálogo, o bilhete, a carta familiar, a lista de compras. Já os secundários, considerados complexos, encontram-se na escrita e surgem nas condições de um convívio cultural, isto é, são artificiais. São exemplos o discurso político, o texto científico, o romance etc. Os gêneros secundários absorvem e transformam os primários, tornando-se um componente do outro.

Se concebermos a linguagem na abordagem sócio-histórica, pensamos o ensino-aprendizagem nesta concepção e partimos dos gêneros, enquanto concretização e manifestação viva da linguagem, como um caminho/instrumento para o ensino da língua numa organização curricular progressiva, "[...] ou seja, a organização temporal do ensino para que se chegue a uma aprendizagem ótima [...] uma progressão curricular centrase em conteúdos disciplinares que se supõe que coloquem problemas para os aprendizes de um ciclo" (DOLZ \& SCHNEUWLY, 2004, p. 43 e 50). Conforme os autores, essa progressão ocorre, na prática, por meio de uma seqüência didática, entendida como um conjunto de atividades escolares organizadas de maneira sistemática a partir de um gênero oral ou escrito. É estruturada em módulos e constituída por várias atividades realizadas de maneira sistemática e aprofundada. "O trabalho escolar, no domínio da produção de linguagem, faz-se sobre os gêneros, quer se queira ou não. Eles constituem o instrumento de mediação de toda estratégia de ensino e o material de trabalho, necessário e inesgotável, para o ensino da textualidade" (DOLZ \& SCHNEUWLY, 2004, p. 51).

\section{Contextualização do diagnóstico}

Realizamos a pesquisa diagnóstica no curso de Letras, da Universidade Estadual de Maringá, nos anos de 2004/2006. Esta se revelou qualitativo-interpretativa, de cunho-etnográfico e de natureza aplicada. Nosso objetivo era diagnosticar que abordagem(ns) dos conteúdos gramaticais orientava $(\mathrm{m})$ a prática docente dos professores de Língua Portuguesa e verificar de que forma a(s) abordagem(ns) se refletia $(m)$ na ação docente dos professorandos. Para isso, observa- 
mos e relatamos 18h/a nas disciplinas de Língua Portuguesa I - Expressão Escrita e Compreensão de Texto, primeiro ano - professor A; Língua Portuguesa II: Morfologia, segundo ano - professor B; Língua Portuguesa III - Sintaxe da frase ao texto, terceiro ano, professor C; Língua Portuguesa IV: Semântica e Estilística, quinto ano, professor D; Prática de Ensino de Língua Portuguesa - quarto ano, professor E. Além disso, analisamos também as ementas dessas disciplinas e o projeto político-pedagógico do curso.

Essa escolha teve dois motivos: primeiro, por serem disciplinas específicas, três delas oferecem um ensino explícito de gramática. Cenário escolhido para verificar a abordagem gramatical, o conceito de gramática, os conteúdos ensinados e a concepção de linguagem dos professores formadores; segundo, por serem esses os professores pelos quais passaram e iriam passar os alunos de Prática de Ensino, ter-se-ia uma referência para cotejar a aproximação da formação recebida e da prática assumida pelo professorando. Por essa razão, a disciplina Prática de Ensino é inserida na pesquisa, pois, ao cursá-la, o aluno encontra efetivamente a oportunidade de atuar como professor.

Os alunos, foco desta pesquisa, compunham a turma única do quarto ano Português/Inglês, matutino, do ano de 2004, do curso de Letras da Universidade Estadual de Maringá, matriculados na disciplina Prática de Ensino de Língua Portuguesa. Como as turmas de Letras, em geral, são muito numerosas, para que haja uma melhor interação entre professor e aluno, normalmente, procura-se dividir a turma entre dois ou mais professores. Isso aconteceu com o quarto ano, dividido entre dois professores.

Entre os professorandos, escolhi sete para acompanhar na regência, divididos, posteriormente, em duas duplas e um trio de alunas, pelo professor da disciplina. As professorandas são identificadas como dupla I, dupla II e trio. A dupla II, a que nos interessa neste trabalho, realizou a regência no período matutino, numa escola estadual de periferia, na cidade de Maringá, no ensino fundamental, $7^{a}$ série, somando seis horas/aula. O conteúdo proposto foi a estrutura da notícia. Como o nosso objetivo é apresentar uma proposta de intervenção para o gênero notícia, abordado em sala por esta dupla, descartamos, neste trabalho, as demais aulas observadas no curso. 
Para a análise das aulas dos professores e das professorandas, estabelecemos como critérios de análise o conteúdo trabalhado em sala, a abordagem teórica a ele dispensada, o tipo de aula - expositiva ou interativa -, bem como as concepções de língua, linguagem e de gramática.

\section{Relato das aulas}

Ao iniciarem a primeira aula, as professorandas se apresentam à $7^{\mathrm{a}}$ série. Em seguida, solicitam aos alunos que o façam individualmente, acrescentando às suas falas o que mais gostam de fazer. Depois, propõem como atividade escrita um texto em que os discentes contem o que mais gostam de fazer e por quê. Os alunos estavam confusos sobre essa atividade e perguntam como escrever sobre o que gostam. Uma das professorandas explica para não fazerem o texto simplesmente dizendo: "meu nome é Pedro e adoro dançar." Mas sim, de forma elaborada. Entretanto, elas não lhes explicaram como seria um texto elaborado. Posteriormente, comentam que com essa atividade têm como objetivo avaliar o nível de argumentação da turma. Alguns dos alunos perguntam o que é argumentar. Elas respondem que é expor a sua opinião a alguém e convencê-la de que a sua opinião está adequada. "Nós, professoras, queremos saber o que vocês gostam de fazer e por que, e, ao dizer o porquê, vocês devem nos convencer a respeito disso". Alguns discentes ainda se mostram confusos a respeito da argumentação. As orientadoras explicam novamente "quando pedem alguma coisa aos pais e eles dizem não e vocês conversam, explicam, mostram, a fim de convencê-los a atendê-los em seus pedidos, vocês estão argumentando." Logo, "argumentar é tentar conhecer a outra pessoa, usando argumentos, motivos, razões, os quais levariam seus pais a atenderem aos seus pedidos." Assim, elas afirmam, "Vocês argumentem para mostrar, por exemplo, por que gostam de pipoca. Procurem explicar, pois, se disseram que gostam, terão que dizer a razão." E complementam acrescentando que "o fato de alguém ler sobre engenharia genética, nos jornais, não é garantia para gostar. Para explicar por que gostam, vocês precisam conhecer, por exemplo, 
se for o caso, obre a engenharia genética." Depois disso, os alunos escrevem os textos, restando apenas uns vinte minutos de aula para realizarem a atividade, já que, após o intervalo de uma aula, ao retornarem à sala, as professorandas não deram continuidade à tarefa.

Ao iniciarem a segunda aula, solicitam aos educandos que sentem em grupos de três a quatro alunos. Entregam uma notícia para cada grupo e dizem que vão estudar a estrutura da notícia. Ressaltam que toda notícia é construída levando-se em conta cinco perguntas respondidas ao longo do texto e escrevem no quadro o quê, como, quando, onde e por que. Pedem aos alunos que leiam as notícias e encontrem as respostas para essas cinco perguntas e, uma vez feito isso, cada grupo vai apresentar sua notícia para os outros grupos. Concluída essa fase, as professorandas iniciam as apresentações com perguntas sobre a notícia analisada, de modo que a equipe respondesse e compreendesse o uso do quê, como, quando, onde e por que, na estrutura da notícia. Os grupos não tiveram dificuldades em responder às perguntas feitas.

Ao retornarem, no dia seguinte, numa aula de quarenta e cinco minutos, pedem aos alunos que formem novamente os grupos da aula anterior. Em seguida, retomam a discussão a respeito da estrutura da notícia. Perguntam-lhes quais itens devem ser analisados. Os discentes respondem o quê, como, quando, onde e por quê. Elas transcrevem no quadro alguns fragmentos das notícias analisadas pelos grupos e discutem outra vez sobre as perguntas que devem contemplar uma notícia. Ao final da aula, solicitam aos aprendizes que tragam, para a próxima aula, uma notícia que tenham lido ou ouvido.

$\mathrm{Na}$ aula seguinte, requerem a tarefa. A maior parte dos educandos não a fez. Elas lêem as dos que a fizeram e comentam que houve uma confusão em relação à causa e à consequiência. Explicam que, ao lerem a notícia, devem observar aquela pergunta que colocaram como primeira no quadro, pois ela se refere ao assunto. "O que é o que acontece". Citam como exemplo uma notícia que retrata um acidente no Líbano, que matou cinco pessoas. Mostram para os alunos que, nessa notícia, primeiramente, deve-se anunciar "cinco mortos em acidente", ou seja, o que aconteceu. Já o porquê talvez seja o carro que se desgovernou, ou o motorista que estava bêbado, ou ainda as duas coisas. Usam como segundo exemplo uma notícia de um aluno: Casas foram arrastadas e 
seis mortos. Como? - perguntam. Vento de mais de $600 \mathrm{~km} \mathrm{~h}^{-1}$ - respondem. Onde? Na Flórida. Quando? E por que, é o furacão. Explicam que, se o aluno tivesse colocado o furacão para responder a pergunta o quê? deixaria de anunciar a notícia mais importante. Complementam que, na notícia, normalmente o que está expresso na manchete é a consequiência do que aconteceu. Uma das educadoras pergunta se alguém sabe explicar o que é a manchete. Um aluno responde ser o que vem escrito em letra maior. Ela questiona se os discentes sabem por quê. Alguém completa que é para chamar a atenção do leitor. A professoranda observa que a manchete deve contemplar as principais informações da notícia. Ressalta ainda que os aprendizes devem se conscientizar de que ler só as manchetes trazidas nos jornais não é suficiente para a compreensão de um fato, uma vez que são feitas exatamente para chamar a atenção do leitor e, se o jornal não for bom, pode transmitir uma idéia errada do que está escrito no corpo da notícia. Às vezes, pode ter a manchete e não ter a notícia. Comenta que a Folha de Londrina trouxe uma manchete sobre o processo de Belinatti (ex-prefeito de Londrina), porém, no jornal, não havia a notícia. Isso ocorre para chamar a atenção do leitor. Explica-lhes que existem vários tipos de jornais e diferentes modos de escrevê-los. A Folha de S. Paulo e o Estado de S. Paulo percorrem todo o país e são jornais mais elitizados. Também há os jornais populares que tratam a notícia de forma mais escraxada. Em São Paulo, por exemplo, existe o jornal Notícias Populares que só apresenta notícias de mortes, assassinatos. Depois disso, ela pergunta aos alunos quais jornais existem no Estado do Paraná. Os educandos respondem Folha do Paraná, Hoje, O Diário. Pede que citem outro jornal que traz notícias e reportagens que dizem respeito a todo país, entretanto, não obtém resposta e acrescenta que é o Jornal Nacional, transmitido na televisão. Pergunta ainda sobre um jornal local, transmitido também pela televisão. Eles respondem Paraná TV. Depois disso, a estagiária informa que, na próxima aula, que será antes do intervalo, escreverão uma notícia.

Quando retornaram à aula, explicaram que, ao escreverem a notícia, deveriam fazê-la em corpo de texto, conforme viram em sala. "Ao abrirmos o jornal e lermos uma notícia, nela não está escrito o quê, como, quando, onde e por que. Nós as descobrimos ao ler o texto". Ressaltaram ainda para escreverem a notícia toda e não só a manchete. 
Depois perguntaram aos alunos qual era o objetivo dessa atividade e para quem iam escrevê-la e responderam que as dez melhores notícias seriam colocadas num mural em sala de aula. Ao final da aula, os alunos entregaram os textos feitos às estagiárias, que, no dia seguinte, após comentarem alguns problemas de ordem formal, solicitaram a reescrita.

\section{Análise}

O relato das aulas evidencia um momento de interface entre as concepções de ensino tradicional e interacionista vivido pela dupla II. A primeira aula traz um misto de características dessas abordagens de ensino. O encaminhamento da atividade de produção de um texto, a partir do nada, sem atividade prévia, como a leitura de jornais e destaque de notícias, por exemplo, sem nenhuma ligação com o conteúdo trabalhado na aula seguinte, e a aparente finalidade de avaliar os alunos tendo em vista um "interlocutor" preocupado com o produto final do educando são marcas da concepção de ensino tradicional, em que a escrita é concebida como dom e conseqüência. Entretanto, o exercício de escrita foi solicitado com o objetivo de também estabelecer uma interação com a turma, o que aconteceu de fato em aula, conforme relata um membro da dupla:

Tendo em mente que o relacionamento humano é tão importante quanto a erudição no processo de aprendizagem (Weber, 1986), buscamos estabelecer um primeiro contato com a turma e ao mesmo tempo uma oportunidade de observá-los em relação às habilidades oral (num primeiro momento) e escrita. Pedimos que cada um se apresentasse e dissesse-nos qual era a sua atividade favorita [...] Após ouvi-los, pedimos que cada um escrevesse as mesmas informações que havia dado oralmente e a elas acrescentasse a razão da preferência por tal atividade (Diário Reflexivo' ${ }^{1}, \mathrm{~s} / \mathrm{p}, 2005$ ).

A proposta de estudo da estrutura da notícia, a partir da segunda aula, parece enfatizar aquilo que constitui uma das partes que compõe 
o gênero notícia: a sua estrutura composicional. Assim, a dupla II enfatiza nas aulas o aspecto descritivo do que seja uma notícia. E por essa razão, centra-se mais na reflexão metalingüística - estrutura do texto -, com maior ênfase na quarta aula quando explica a respeito da organização e apresentação das informações no texto, por meio das perguntas $o$ que, como, quando, onde e por que.

Ao realizar os estudos filosóficos da linguagem, Bakhtin (2003, p. 283) observa que "[...] aprender a falar significa aprender a construir enunciados porque falamos por enunciados e não por orações isoladas, e evidentemente, não por palavras isoladas", nem por exercícios aplicados apenas divorciadamente das práticas de usos efetivos da linguagem, sem que exista um objetivo claro e definido que possa justificá-los. Diferentemente disso, a dupla II parte do uso para a reflexão lingüística, uma vez que inicia o estudo do conteúdo com a leitura de notícias, textos de circulação social. Logo, favorece que o aprendiz desenvolva o conhecimento metalingüístico em situações concretas de uso. Nesse sentido, é possível que tenha realizado a explicação dos aspectos estruturais e da organização do texto, tomando como ponto de partida a definição, fato ocorrido em todas as aulas.

Além disso, as professorandas manifestam, ainda que implicitamente, uma preocupação com o leitor/interlocutor, quando pediram aos alunos, na quarta aula, o modo de organizarem e apresentarem as informações para que estas ficassem claras no texto, postura que se repete no momento em que fazem observações sobre a necessidade de se contemplar na manchete as principais informações da notícia.

Apesar de existirem características do interacionismo em boa parte das aulas, a revisão dos textos escritos, feita pelas estagiárias, ocorre de maneira tradicionalista, uma vez que estas se prenderam apenas ao aspecto estrutural do texto. Assim, um membro da dupla relata: "Devolvemos aos alunos os seus textos, pedimos que cada um verificasse seus erros e que observando a correção refizessem-no" (Diário Reflexivo, s/p, 2005). Isso é um indício de como a produção escrita foi realizada e internalizada nos anos escolares que antecederam à graduação da dupla. Difere, portanto, da ${ }^{2}$ primeira dupla que conduziu a revisão das produções por meio de comentários interativos dos colegas e das professorandas. 
O modo de conceberem alguns exercícios evidencia nas aulas uma mescla de características das abordagens de ensino tradicional e interacionista. Dessa forma, a dupla II parece estar num momento de interface entre uma e outra concepção, o que pode ser reflexo do percurso de internalização da concepção de ensino de língua portuguesa no qual ela se insere - a de que ensinar língua é ensinar gramática. Concepção cristalizada pela tradição e revelada pela sociedade e por grande parte dos professores atuantes nos ensinos fundamental e médio.

A natureza descritiva das disciplinas de morfologia e de sintaxe reforça essa visão. Além disso, no curso de Letras/UEM, as disciplinas são vistas geralmente de maneira estanque. Conseqüentemente, nessa fase de ensino, o professorando internaliza o conhecimento, também, dessa maneira fragmentada e, ao chegar à prática de ensino, repete $\mathrm{o}$ que apreendeu. Não é possível ser um mediador de conhecimentos, se nessa perspectiva o aprendizado não ocorreu. É a partir do modo de interação professor-aluno-conteúdo, transformado e organizado individualmente durante os anos de formação escolar - ensino fundamental, médio e também em algumas disciplinas do curso de Letras -, que os conteúdos apreendidos foram posteriormente exteriorizados pelas professorandas, sobretudo, porque "todas as funções superiores originam-se das relações reais entre indivíduos humanos". (VYGOTSKY, 1988, p. 64). Além do mais, os professores, não apenas os do curso de Letras, são vistos como o instrumento externo e, portanto, exercem o papel do instrumento ressaltado por Vygotsky, na mediação da realização de uma operação. "A função do instrumento é servir como um condutor da influência humana sobre o objeto da atividade; ele é orientado externamente [...] constitui um meio pelo qual a atividade humana externa é dirigida para o controle da natureza" ( p. 62).

Síntese das características observadas nas aulas da dupla II:

- Usa a linguagem numa concepção de interface entre o ensino tradicional e o ensino interacionista;

- Propicia o estudo de um gênero textual;

- Estimula a reflexão lingüística e metalingüística; 
- Considera o interlocutor nas atividades;

- Orienta e incentiva a etapa da reescrita de modo tradicional;

- Estabelece a interface entre as concepções de escrita como consequiência e como trabalho.

\section{O gênero notícia}

Como destaca Barbosa (2001), a notícia consiste em apresentar um fato ou acontecimento. O próprio termo, em inglês news e em francês nouvell, significa também novas, novidades, informação, o que indica uma característica da notícia: apresentar algo que seja novo. Em Barbosa (2000), temos a notícia como matéria-prima do jornal, em que se salienta que, por mais que os jornais tenham diversificado suas seções e tenham incorporado e desenvolvido diferentes gêneros, boa parte dos consumidores de jornais compram esse periódico em função das notícias.

Barbosa (2001) assinala que, na busca pelo novo, as novidades escolhidas são aquelas que têm boas chances de chamar a atenção de um grande número de leitores, como as que estão calcadas em tragédias: mortes, desastres, guerras, acidentes, brigas, escândalos e acontecimentos sensoriais. Além desses, também são noticiados fatos políticos, econômicos, esportivos, culturais. O critério de escolha do fato a ser noticiado é justamente o que possa atingir e interessar o leitor e a própria sociedade. Assim, os jornalistas procuram chamar a atenção do leitor ao provocar-lhe sensações e despertar-lhe a sua curiosidade.

À luz da autora, são estratégias para se capturar o leitor a manchete e o título da notícia. Esses normalmente manifestam-se com o tempo no presente, o que causa um efeito de aproximação entre leitor e fato. Melo (1985) explicita que os títulos e manchetes ocorrem de duas formas: os que emitem claramente um ponto de vista e os que dissimulam o conteúdo ideológico. Comenta, ainda, que o exame das manchetes de primeira página permite discernir a personalidade política dos jornais. 
Nesse sentido, Barbosa (2000) explica que a escolha lexical está relacionada não só ao gênero, mas também a questões ideológicas e ao veículo em que o texto será impresso, o tipo de jornal. Mostra que há uma sinonímia entre os termos corpo, defunto, presunto e cadáver e usar um ou outro tem implicações ideológicas. Desse modo, em um jornal do tipo A dificilmente encontra-se o termo presunto, enquanto que em um jornal tipo $\mathrm{C}$, o termo pode ser usado. Nessa instância também se procura conciliar a linguagem de uso coloquial com a de uso formal.

Além disso, há a existência de enunciados mais referenciais e inexistência de enunciados opinativos. A presença do modo indicativo; uso da terceira pessoa e marcas de impessoalidade, por meio do pronome oblíquo se. É comum utilizar as passivas sintética e analítica. Com o intuito de fornecer dados para que o leitor faça a sua avaliação, evitam-se assim adjetivos testemunhais e subjetivos como alto, chocante, bela, próspero. Quase sempre o verbo principal do lead aparece nos tempos perfectivos - perfeito, quando a notícia é de fato acontecido, ou futuro do presente, se a notícia anuncia fato previsto. Isso oferece maior especificidade ao fato, que é apresentado como concluído ou provável de acontecer.

Conforme Dolz e Schneuwly (2004), esse gênero discursivo pertence à ordem do relatar. Explicitam Barbosa (2000) e Lage (2002) que a notícia inicia-se por um Lead, presente já no primeiro parágrafo, e este deve informar quem, o que, a quem, quando, onde, como, por que e para quê, de modo a mastigar para o leitor as informações e assim tornar a notícia mais compreensível e rápida de ser lida e, é claro, capturar o leitor. Para tanto, não basta que essa seja verdadeira, antes é preciso que ela pareça verdadeira. As informações são ordenadas não por sua seqüência temporal, mas pelo interesse ou importância decrescente na perspectiva de quem conta e principalmente na perspectiva de quem ouve.

Levando em consideração essas questões aqui delineadas e os estudos de Dolz e Schneuwly (2004), Perfeito (2005) e Barbosa (2000, 2001), apresentamos uma sugestão para o trabalho com a notícia em sala de aula que vá além de sua estrutura composicional, já que esta é uma das partes que compõe tal gênero. 


\section{A notícia na sala de aula: apresentação de uma proposta}

Ancorados no esquema da sequiência didática proposto por Dolz et al. (2004), sugerimos que o trabalho se inicie pela apresentação da situação na qual se exponha aos alunos um projeto de comunicação a ser desenvolvido, em que fique claro a eles o gênero que será trabalhado, notícia, e a sua finalidade que pode ser a publicação, via sorteio em sala, de duas notícias no jornal do colégio e/ou da cidade, e as demais serem publicadas no mural do colégio. Definimos também que a forma da produção será impressa e delineamos, inclusive, os três tipos de interlocutor apresentados por Bakhtin/ Volochinov (1992): o real, que será o professor, o virtual, alunos do colégio, e o destinatário superior ou ideologia dominante no estabelecimento de ensino e/ou do jornal.

Nessa fase, como mostram os autores, é necessário também apresentar o conteúdo temático, no caso, acidentes aéreos e a sua importância. Motivar os alunos ao estudo desse tema é uma tarefa que pode ser feita mediante a exibição de fotos e imagens de acidentes aéreos para provocar polêmica e um debate em sala.

Feito isso, dando seqüência à atividade, sugerimos, como primeira produção e primeiro contato com o gênero a escrita de um texto que noticie um acidente qualquer e de escolha do aluno. Nessa atividade, os aprendizes terão como interlocutores a própria turma. Afirmam os autores que, neste momento, o exercício proposto tem um papel central regularizador da sequiência didática, tanto para os alunos como para o professor. Para os alunos, concretiza os elementos explicitados na apresentação da situação e traz esclarecimentos acerca do gênero a ser estudado, além de lhes permitir a descoberta do que já sabem fazer e conscientizar-se do que não sabem. Assim, propomos que, feita a produção, cada aluno exponha a sua notícia em sala, para que na interação professor/aluno sejam observadas as capacidades e os problemas que precisam ser sanados. É o momento de o professor conhecer a turma em relação aos saberes que o gênero proposto mobiliza e verificar que capacidades necessitam ser desenvolvidas. E aqui a seqüência didática tem seu início, pensada e organizada num contexto de ensino-aprendizagem específico. 
Considerando-se tais aspectos, observamos as atividades realizadas pela dupla II como desconexas de um processo contínuo de ensino e um tanto mais artificiais, por terem enfatizado somente a estrutura da notícia. A esse respeito, resgatamos Barbosa (2000, p. 160):

Ora, como saber qual o aspecto mais relevante a ser destacado, sem levar em conta elementos das condições de produção, tais como: em que jornal a notícia está ou será publicada; qual o tipo de leitor suposto; qual o objetivo maior desse jornal; qual posicionamento ideológico mais geral desse jornal; é possível relatar fatos de forma totalmente neutra; quais fatos viram notícias e por quê; por que o lead adquiriu essa forma padronizada, etc.

Assim, para que o aluno se aproprie dos instrumentos de linguagem próprios aos gêneros, é preciso organizar o seu ensino numa perspectiva que abarque o gênero em quatro dimensões. Nessa perspectiva, Perfeito (2005, p. 61) apresenta uma proposta a ser utilizada na análise de textos de variados gêneros no espaço escolar:

- Contexto de produção e relação autor/leitor/texto observação de aspectos relativos ao/à: autor/enunciador, destinatário, provável objetivo, local, época de publicação e de circulação; exploração das inferências, das críticas, das emoções suscitadas; criação de situações-problema e de transformações, veiculadas a efeitos de sentido do texto etc. - Conteúdo temático - temas que são tratados em textos pertencentes ao gênero em questão.

- Organização geral (construção composicional) estrutura, o arranjo textual.

- Marcas lingüísticas e enunciativas - características do gênero (lingüísticas) e do autor (enunciativas), o qual veicula seu texto, fundamentalmente, um gênero (recursos lingüístico-expressivos mobilizados).

Observando-se esses aspectos nos problemas levantados a partir da produção da notícia, podemos pensar numa sequiência de atividades 
que se organize em módulos. Suponhamos que os alunos tenham tido dificuldades para construírem a manchete ou que tenham deixado de fazêla em seus textos. No módulo I, proporíamos à sétima série, como primeiro passo, o estudo das condições de produção que envolvem o construto de uma notícia, para mostrar-lhes que uma manchete, assim como toda a notícia, não é um enunciado aleatório. Usaremos para isso uma notícia da Folha de S. Paulo, de 05/08/07, cuja manchete traz o seguinte enunciado: Tragédia em Congonhas pode se repetir, dizem estudiosos. Assim, propomos como atividades prévias antes leitura da manchete:

- Você sabe o que é um jornal?

- Você já leu algum jornal? Qual(s)?

- Seus pais lêem jornal? Qual(s) Com que freqüência?

- Para que serve o jornal?

- Você considera o jornal como um meio de comunicação importante? Por quê?

- O que o jornal oferece as pessoas?

- Você gosta de ler jornal? O que o atrai para a leitura de um jornal?

- Maringá possui um jornal local? Qual é o nome? Paraná?

- Quais são os jornais mais conhecidos do estado do

- Você conhece algum jornal que não seja do Paraná? Qual?

- Você sabe o valor de um jornal?

- Você sabe como o jornal organiza os diversos assuntos?

- O que o jornal apresenta na primeira página?

- Você sabe o que é uma notícia?

-Você sabe o que é uma manchete?

Realizada a discussão, passamos para a leitura da manchete e discussão com a turma a respeito do que ela traz como tópico. Depois faremos o levantamento de hipóteses a respeito do que será apresentado no corpo do texto e a comparação das informações ali mostradas com o que diz a manchete. Feito isso, passamos para a terceira fase em que serão apontadas questões referentes à relação autor/leitor/texto: 
- Onde foi publicada esta notícia?

- Quem lê esse tipo de texto?

- Você já leu alguma notícia publicada neste jornal?

- Seus pais leem este jornal?

- Você conhece outras pessoas que leem este jornal? Quem?

- Esta mesma notícia pode ser encontrada em outro jornal?

- A manchete chama a atenção do leitor?

- Quem escreveu esta notícia?

- Qual é o objetivo desta notícia?

- A notícia é interessante? Para quem?

- Quando foi publicada?

- Existe uma relação entre a situação vivida pelo país e o que traz a notícia?

- De que maneira e onde essa relação se manifesta nesta notícia?Escreva em seu caderno.

Dando continuidade a atividade, no módulo II, passamos ao tratamento do tema:

- O texto fala sobre o acidente com o avião da Tam e sobre a possibilidade de ocorrer outro acidente. O que você sabe a respeito desse acidente?

- Você possui conhecimento a respeito de outros acidentes aéreos?

- Quando e onde ocorreram?

- Quais meios você usou para acompanhar as informações a respeito do acidente com o avião da Tam?

- Você acha o avião um meio de transporte importante? Por $q u \hat{e} ?$

- Quem é a Tam?

- Você já foi a um aeroporto?

- Você sabe o que é tráfego aéreo?

- Qual é o tema da notícia apresentada na Folha de S. Paulo?

- Na sua opinião, o que aconteceu com o avião da Tam foi um acidente? Por quê?

- Pesquise, em três jornais distintos, notícias a respeito do 
acidente da Tam para apresentação e discussão em sala. Em que aspectos elas se diferenciam?

- Observe a construção da manchete nos três jornais. Em que aspectos elas se diferenciam?

Dando seqüência a atividade, no módulo III, enfocamos, nessa etapa, a estrutura composicional do gênero notícia.

- A notícia Tragédia em Congonhas pode se repetir, dizem estudiosos traz informações sobre um acontecimento? Qual?

- Este acontecimento ocorreu num cenário e envolveu pessoas? Em que cenário e quais eram as pessoas?

- Como as informações são apresentadas? Existe uma ordem na exposição dos fatos? O que é mostrado primeiro?Por quê?

- É possível reconhecer no texto em que época esse fato aconteceu e de que maneira? O que provocou o acontecimento?

- As informações estão organizadas em quantos parágrafos?

- A manchete informa com antecedência o assunto?

Para atingir a análise lingüística, sugerimos, no módulo IV, os seguintes procedimentos:

- Há marcas de temporalidade na manchete? Como se manifesta $(m)$ ? Causa $(m)$ algum efeito?

- Há marcas de temporalidade na notícia? Qual é o tempo revelado aqui? Há mais de um tempo? Por quê?

- Há marcas de subjetividade? Objetividade? Quais? Isso acarreta algum sentido para a notícia? Qual?

- O termo tragédia confere algum sentido ao texto?

- No lugar da palavra tragédia, o jornal poderia ter usado outra sinônima? Qual?

- Como o discurso é manifestado? Em primeira ou terceira pessoa?

- O que revelam os usos do termo segundo em "segundo dois dos mais conhecidos..." e "segundo a reportagem...?”.

- Por que o uso dos verbos no modo indicativo? O que este modo significa? 
- A linguagem usada é adequada ao tipo de leitor a que destina a notícia?

Feito esse percurso, propomos como atividade que mobilize as capacidades desenvolvidas neste caminho, a produção escrita.

- A produção será feita individualmente.

- Pondo em prática os conteúdos estudados, "Imagine que as investigações do acidente que envolveu o avião da Tam tenham terminado e o piloto do avião tenha sido indicado como o principal responsável pela causa do acidente. A partir disso, crie uma notícia em que você, redator da Folha de S. Paulo, anuncie esta informação.” Pense no leitor que você quer atingir e selecione os recursos lingüísticos adequados à situação comunicativa e ao gênero notícia. As duas notícias que se destacarem serão publicadas no jornal da escola e no jornal da cidade. As demais serão expostas no mural Acontecimentos do nosso colégio. Para tanto:

- Planeje a escrita de seu texto. Nessa etapa, considere a finalidade do texto, informar e o leitor que quer atingir, os colegas do colégio, professores, funcionários e a comunidade maringaense, em geral.

- Escrita: mobilize os conhecimentos que você adquiriu em sala no que tange o tema, a notícia, o tipo de linguagem e os recursos necessários para alcançar a sua finalidade de escrita.

- Revisão do texto e entrega.

- Exposição oral das notícias em sala para os colegas.

- Troca de textos com os colegas.

- Revisão feita pelo professor.

- Revisão feita pelos colegas.

- Reescrita.

- Publicação.

\section{Conclusão}

A partir da pesquisa o ensino de gramática no curso de Letras/ UEM e seus reflexos na prática pedagógica dos formandos, que teve os objetivos de averiguar as concepções de ensino de língua, linguagem e de 
gramática que dão suporte às aulas ministradas pelos futuros professores, verificou-se que essa dupla de professorandas apresenta uma interface entre as concepções de linguagem tradicional (estruturalista) e interacionista. As atividades solicitadas revelam uma preocupação com a transmissão do conteúdo com ênfase na estrutura do gênero notícia.Assim, mostram uma concepção de ensino subjacente às concepções que lhe são anteriores. Se a língua é estática, a linguagem é um meio de estabelecer a comunicação e a gramática é uma estrutura pronta, o papel do professor, e nessa pesquisa, do professorando, é transmitir informações e o do aluno recebê-las. Analisou-se que isso é reflexo do percurso de internalização ocorrido durante os anos de formação no curso de Letras. Apesar de alguns professores desenvolverem suas aulas na perspectiva interacionista, as disciplinas são vistas de maneira estanque, e o professorando consequentemente não consegue fazer a ponte entre elas, e assim ele reflete na sua prática o conhecimento fragmentado, da maneira como o internalizou. As disciplinas que envolvem o ensino de gramática no curso também possibilitam essa resposta, pois, em algumas, constrói-se a noção de que ensinar língua é ensinar a gramática normativa. O professorando, por sua vez, tenta assumir uma postura interacionista em sala e trabalhar os conteúdos de modo construtivo com seus alunos, porém, como essa não é a característica que predomina em sua formação, ele reproduz aquela que está enraizada.

Se por um lado vemos uma concepção de linguagem ainda operante aos moldes tradicionais, por outro, vemos também uma concepção de linguagem viva revelada na própria interface. Isso significa que, a partir da noção de internalização, a reconstrução da visão de gramática efetivada no curso de Letras tem alterado a gramática do sujeito-aluno, no seu uso e nas suas concepções. Além disso, evidencia que o fato de não saber fazer transposição da teoria para a prática é uma questão que impede o professorando de realizar em sala atividades que evidenciem a linguagem no seu uso e funcionamento.

Considerando esses aspectos, tivemos como objetivo apresentar uma sugestão para o tratamento do gênero notícia em sala de aula numa seqüência didática. 


\section{Notas}

'Emiliano, S. R. Dissertação de mestrado "O Ensino de Gramática no curso de Letras: Diagnóstico de uma Realidade.” Universidade Estadual de Maringá. Maringá, março/2006. Pesquisa vinculada ao grupo de Pesquisa "Interação e escrita no ensino e aprendizagem" (UEM/CNPq).

${ }^{2}$ Mestre em Letras pela Universidade Estadual de Maringá - Maringá/PR e professora lotada no Departamento de Letras desta instituição. Área de atuação: Estudos Lingüísticos. Departamento de Letras, Universidade Estadual de Maringá, Av. Colombo, 57020-900, Maringá, Paraná, Brasil. E-mail: silviareginaemiliano@yahoo.com.br.

${ }^{3}$ Trata-se do dossiê que os professorandos devem entregar no final do ano letivo ao professor de Prática de Ensino, com os relatórios de todas as atividades práticas desenvolvidas em estágio de observação, participação e a regência. Além de descrever as situações vividas, precisam informar, confrontar e reconstruir, sugerir outros encaminhamentos às atividades. É um requisito para a aprovação na disciplina. Os dossiês foram concedidos a mim pelo professor de Prática de Ensino de Língua Portuguesa em outubro de 2005.

${ }^{4}$ Ver Emiliano, S. R. Dissertação de mestrado "O Ensino de Gramática no curso de Letras: Diagnóstico de uma Realidade.” Universidade Estadual de Maringá. Maringá, março/2006.

\section{Referências}

BAKHTIN, M./VOLOCHINOV. Marxismo e filosofia da linguagem. 6. ed. São Paulo: Hucitec, 1992.

BAKHTIN, M. Estética da criação verbal. 4. ed. São Paulo: Martins Fontes, 2003.

BARBOSA, J. P. In: ROJO, R. (Org). A prática de linguagem em sala de aula: praticando os PCNs. São Paulo: Educ; Campinas: Mercado de Letras, 2000. p. 149-182.

BARBOSA, J. P. Trabalhando com os gêneros do discurso: relatar - notícia. São Paulo: FDT, 2001.

DOLZ, J.; SCHNEUWLY, B. In: ROJO, R.; CORDEIRO, G. S. (Ed.). Gêneros orais e escritos na escola. Campinas: Mercado de Letras, 2004. p. 41-60.

DOLZ, J. et al. In: ROJO, R.; CORDEIRO, G. S. (Ed.). Gêneros orais e escritos na escola. Campinas: Mercado de Letras, 2004. p. 95-128. 
LAGE, N. Estrutura da notícia. São Paulo: Ática, 2002.

MELO, J. M. A opinião no jornalismo brasileiro. Petrópolis: Vozes, 1985.

PERFEITO, A. M. Concepções de linguagem, teorias subjacentes e ensino de língua portuguesa. In: Concepções de linguagem e ensino de língua Portuguesa (Formação de professores EAD 18). 1. ed. v. 1. Maringá: Eduem, 2005. p. 27-79.

VYGOTSKY, L. S. A formação social da mente. 2. ed. São Paulo: Ática, 1988.

\section{Anexo}

Cotidiano

05/08/2007 - 09h57

Tragédia em Congonhas pode se repetir, dizem estudiosos da Folha Online

Segundo dois dos mais conhecidos investigadores internacionais de causas de desastres aéreos, o acidente com o Airbus da TAM, em Congonhas (zona sul de São Paulo), pode se repetir se o aeroporto não sofrer mudanças, informa neste domingo reportagem da Folha (íntegra disponível só para assinantes do jornal ou do UOL).

Para os pesquisadores - o inglês Peter Ladkin, professor de computação na Universidade de Bielefeld, na Alemanha, e o norteamericano Kenneth Funk $2^{\circ}$, professor de engenharia da Universidade Estadual do Oregon, nos EUA-, segundo a reportagem, o problema de Congonhas é a falta de área de escape.

No último dia 17, o Airbus-A320 da TAM, que tinha 187 pessoas a bordo, perdeu o controle ao tentar pousar na pista principal de Congonhas, atravessou a avenida Washington Luís e bateu em um galpão da TAM Express. 
O choque provocou um incêndio de grandes proporções.

De acordo com o Corpo de Bombeiros, 220 sacolas com restos mortais de vítimas foram recolhidas no local do acidente. Cerca de 200 pessoas morreram.

Disponível em http://www1.folha.uol.com.br/folha/brasil/ ult96u317886.shtml, acesso em 05/08/2007.

\section{News genres: diagnosis and intervention}

Abstract: A diagnosis research has been undertaken at the Universidade Estadual de Maringá between 2004 and 2006, dealing with the teaching of grammar in the Language Undergraduate Course at the same university and its repercussions in the pedagogical practices of future teachers. The Language Undergraduate Course is thus under focus and current qualitative, interpretative, ethnographical and applied research is based on the social and historical perspective of language. Diagnosis suggested an intervention for teaching and learning of the news genre, within the classroom, by two research subjects. Analysis consisted of the observations and reports of five lessons by two future teachers, in their training period, in the seventh stage of the primary school. Based on the Bakhtinian approach in discursive genres, methods were indicated in the context of the news genre within a didactic sequence.

Keywords: Language Undergraduate Course, diagnosis, intervention, news genres.

Solicitado em jul. de 2008

Aceito em jul. de 2008 